\section{Family perceptions of intensive care unit nurses' roles: a Greek perspective}

\author{
Maria Malliarou,1 Georgia Gerogianni,2 \\ Fotoula Babatsikou, 2 \\ Evaggelia Kotrotsiou, ${ }^{1}$ Sofia Zyga $^{3}$ \\ 1Department of Nursing, Technological \\ Educational Institute of Larisa; \\ 2Department of Nursing A, Laboratory \\ of Community Heath Nursing, \\ Technological Educational Institute \\ of Athens; 3Department of Nursing, \\ Faculty of Human Movement \\ and Quality of Life Sciences, University \\ of Peloponnese, Sparta Lakonias, Greece
}

\section{Abstract}

This study was done in order to examine the role of the nurse in families with critically ill patients as perceived by family members. A descriptive design was conducted with 93 family members aged 18-53 years from a 6-bed intensive care unit in a Greek Hospital. An anonymous self-completed questionnaire recording demographic data and the questionnaire Family members perception of nurses behavioral role expectation/enactment scale of Hickey and Lewandowski was used. Parametric statistic tests were used to examine the research questions. Intensive care unit (ICU) patients' family members expect nurses to make them feel they can ask whatever they want whenever they want, placing great emphasis on communicating with one another and on participating in decision making to the progress of patient care. The age seems to correlate with the expectation from nurse to meet the role of training on how to handle the patient. Nurses did well with regard to meeting family members' expectations. Most family members assessed positively the role of ICU nurse confirming the need for communication, and clear support of families.

\section{Introduction}

Intensive care unit (ICU) nurse's role is complex. Monitoring, adjusting interventions and medications, and collecting subsequent information are some of the procedures needed to be handled. ICU nurse works in an area of high technology and critical changes in vital functions, so she/he must develop separate skills. Not only do the professionals in these units face situations of serious illness, but they also come into contact with the uncertain- ty and anxiety of family members. Nurses need to be aware of family members' needs and expectations so that effective support strategies can be implemented and family satisfaction can be maximized.

Little is known about how families perceive the role of the critical care nurse as it relates to family members. Given the complex role of the ICU nurse investigating how relatives perceive their role is urgent. The admission of a critically ill patient into an intensive care unit is a stressful event for both patients and families.1,2 Because of the fact that critical illness often occurs without warning, families may feel vulnerable and helpless with no clear knowledge of what to expect from nurses. ${ }^{3}$ Additionally, the critical care setting has been regarded as a major stressor because of the complex nature of patients' health problems that require an extensive use of a highly technical environment.4,5 As a result of this, patients' families often experience stress, shock, disbelief, anxiety and depression in a critical care setting. $2,6-10$

Consequently, families need assistance with their own physical and emotional needs, support for their decisions, and help in understanding patients' conditions and treatment options. ${ }^{11}$ This will help them to cope effectively with the stress caused by having their patient in the critical care unit.

It is worth noting that the ability of the family to adapt and provide support to the patient may affect patient's recovery. On the other hand, if the family needs cannot be met, this may have a negative effect on family perception, appraisal, and adaptation to the crisis caused by critical illness. ${ }^{3}$

The role of nurses in the critical care setting is very important in the provision of support and information to these families in order to cope effectively with the stress associated with critical illness. ${ }^{12}$ So, nurses need to be aware of family members' needs and expectations in order to implement strategies to maximize family's satisfaction.1,2 Family satisfaction can be achieved by supportive interventions that focus on decreasing feelings of isolation, strengthen coping efforts, and enhance adjustment to illness. For this reason, nurses should act as mediators and interpret information that help patients' family understand what physicians say and the relevance of that information for a patient's prognosis and decisions about treatment. ${ }^{3}$ Additionally, nurses need to provide effective and immediate psychological support and education to the family because the latter has little control over the patient's condition during the first few days of hospitalization. 13

However, the needs of family members are often overlooked by critical care nurses, because they try to meet the immediate needs of critically ill patients.1,2 Nurses delay, forget,
Correspondence: Sofia Zyga, Department of Nursing, Faculty of Human Movement and Quality of Life Sciences, University of Peloponnese, Leonidou 3, Sparta Lakonias, Greece.

Tel. +30.273 .108 .9725$

E-mail: zygas@uop.gr

Key words: ICU, nurse, family, member, role.

Contributions: the authors contributed equally.

Conflict of interests: the authors declare no potential conflict of interests.

Received for publication: 30 January 2013.

Revision received: 27 February 2013.

Accepted for publication: 27 February 2013.

This work is licensed under a Creative Commons Attribution NonCommercial 3.0 License (CC BYNC 3.0).

(C) Copyright M. Malliarou et al., 2014

Licensee PAGEPress, Italy

Health Psychology Research 2014; 2:994

doi:10.4081/hpr.2014.994

or avoid interacting with family members because they are uncertain about the restoration and preservation of the patient's life and they feel inadequate to convey concerns about critically ill patients to their family. ${ }^{14}$ Additionally, nurses tend to underestimate the needs of family members, who want to have adequate information, to feel accepted by the staff, to feel hope and be informed of changes in the patient's condition. ${ }^{13}$

As a result of this, patients' families often have communication deficiencies, which are an important source of dissatisfaction with critical care.11 Communication deficiencies can be caused by conflicts in critical care settings between nurses and family members. More specifically, nurses and families with diverse cultural backgrounds bring beliefs and understandings that can have a negative impact on the critical care process. 15 Additionally, the highly technical equipment which is used in the treatment of patients and the complicated disease conditions can become barriers to effective communication between nurses and family. 3 Consequently, critical care nurses should assess family needs and foster a sense of optimism in family members in order to encourage them to participate in their patients' care and help them adjust to critical setting. 10,16

\section{Literature review}

Perceptions of family needs of critically ill patients have been addressed in several research studies. Maxwell et al..$^{3}$ conducted a 
study in order to explore nurse and family perceptions of the needs of family members of critically ill patients. Results suggested that the most important needs of family members can be met with assurance, proximity, information, support, and comfort. However, nurses considered the needs of family members as less important than those of patients. ${ }^{3}$

Takman and Severinsson undertook a study in order to explore healthcare providers' perceptions of the needs of significant others in intensive care units in Norway and Sweden. ${ }^{8}$ The results showed that health care providers recognized that the significant others have many individual needs.

In a similar study conducted by GarrousteOrgeas et al. ${ }^{17}$ in order to assess the opinions of caregivers, families, and patients about involvement of families in the care in intensive care unit, they found that families and ICU staff were very supportive to family participation in care.

Although perceptions of nurses about their role with families in an intensive care unit have been described in the literature, little is known about how families perceive the role of critical care nurses as they relate to family members. ${ }^{1}$ Kosco and Warren ${ }^{18}$ found in their study that the importance of family needs, such as the health concerns of family members and freedom of visitation, was perceived differently by nurses and family members. Additionally, Fox et al in their research study about the role of the nurse with families of critically ill patients as perceived by family members found that family members were more satisfied with care when nurses' performance either met or exceeded their expectations. 1

\section{Aim}

This study was done in order to examine the role of the nurse with families of critically ill patients as perceived by family members.

\section{Materials and Methods}

\section{Study design}

Family members perception of nurses behavioral role expectation/enactment scale of Hickey and Lewandowski was used.

Hickey and Lewandowski did not treat their questionnaire as a psychometric instrument and thus did not test its psychometric properties other than content validity.

\section{Procedure}

Individuals participating in the study were informed about the purpose and were assured about the privacy and anonymity of the process. The whole process was dealt by the same person, thus reducing the chances of information leakage and ensured increased trust between researchers and people that took part in the survey.

The inclusion criteria of the sample were the following: i) adults (over 18 years); ii) the desire of individuals to participate in this study; iii) the decision as to whether the conditions for participation in the survey were met was taken by the researchers of this study.

The researchers provided the participants the self-administered questionnaires in sealed ered (in person) back to the researchers in order to preserve confidentiality. The researchers were available for the participants in order to answer any questions throughout the whole process.

\section{Statistical analysis}

Data analysis procedures were performed with the Statistical Package for Social Sciences computer program (version 19). Basic descriptive statistics, such as general frequencies of nominal variables and means of continuous and ordinal variables, were performed to describe the sample characteristics. The $P$ with a value lower than 0.05 was considered as statistically significant result.

\section{Ethical issues}

During the study complete discretion as to the information concerning the examinees envelopes, which after completion they deliv-

Table 1. Characteristics of participating family members.

\begin{tabular}{lcc} 
Characteristics & N & $\%$ \\
Gender & & \\
Man & 15 & 15.4 \\
Woman & 78 & 84.6 \\
Relationship to patient & & \\
Spouse & 39 & 42.3 \\
Offspring & 10 & 11.5 \\
Sibling & 18 & 19.2 \\
Other & 26 & 27.0 \\
\hline Level of education & & \\
Less than high school & 14 & 15.4 \\
High school & 33 & 35.5 \\
Technological institution & 24 & 25.7 \\
University & 22 & 23.4 \\
Marital status & & \\
Single & 4 & 4.3 \\
Widowed & 3 & 3.2 \\
Married & 86 & 92.5 \\
\hline Professional status of family member & \\
Civil servant & & \\
Employee & 22 & 23.65 \\
Private sector & 20 & 21.50 \\
Pensioner & 1 & 1.08 \\
Unemployed & 8 & 8.7 \\
Household & 42 & 45.16 \\
Live with patient & & \\
No & 6 & 38.5 \\
Yes & 57 & 61.5 \\
\hline Live at the place where the hospital is & \\
Yes & 59 & 63.4 \\
No & 34 & 36.6 \\
Age of family member & 93 & $49.4 \pm 4.13$ \\
\hline Weekly visit days & 93 & $4.92 \pm 0.36$ \\
Daily hours with patient & 93 & $1.27 \pm 0.45$ \\
\hline
\end{tabular}

Table 2. Correlation of characteristics of participating family members and their influence on satisfaction score and family expectations.

\begin{tabular}{lcccccc}
\hline Variable & \multicolumn{2}{c}{$\begin{array}{c}\text { Satisfaction } \\
\text { Satisfied }\end{array}$} & Very satisfied & Meeting expectation & Yes \\
Age of family member & $41.4 \pm 3.17$ & $42.3 \pm 3.71$ & 0.196 & $46.6 \pm 3.1$ & $38 \pm 3.6$ & 0.243 \\
Gender & & & 0.547 & & & 0.144 \\
Female & $63(67.74 \%)$ & $15(16.12 \%)$ & & $61(65.59 \%)$ & $17(18.27 \%)$ & \\
Male & $5(5.37 \%)$ & $10(10.77 \%)$ & & $12(12.90 \%)$ & $3(3.24 \%)$ & \\
Total & $68(73.11 \%)$ & $25(26.89 \%)$ & & $70(78.49)$ & $20(21.51)$ & \\
\hline Relationship to patient & & & 0.004 & & & 0.236 \\
Sibling & $4(4.30 \%)$ & $14(15.07 \%)$ & & $15(16.12 \%)$ & $3(3.23 \%)$ & \\
Offspring & $1(1.07 \%)$ & $9(9.67 \%)$ & & $8(8.60 \%)$ & $2(2.16 \%)$ & \\
Spouse & $10(10.75 \%)$ & $29(31.18 \%)$ & & $28(30.10 \%)$ & $11(11.83 \%)$ & \\
Other & $15(16.12 \%)$ & $11(11.84 \%)$ & & $20(21.50 \%)$ & $6(6.46 \%)$ & \\
Total & $30(32.24 \%)$ & $63(67.76 \%)$ & & $71(76.32 \%)$ & $22(23.68 \%)$ & \\
Level of education & & & 0.013 & & & 0.023 \\
Less than high school $4(4.30 \%)$ & $10(10.75 \%)$ & & $7(7.54 \%)$ & $7(7.54 \%)$ & \\
High school & $30(32.24 \%)$ & $3(3.23 \%)$ & & $19(20.40 \%)$ & $14(15.07 \%)$ & \\
Technological & $10(10.75 \%)$ & $14(15.07 \%)$ & & $18(19.33 \%)$ & $6(6.46 \%)$ & \\
University & $15(16.12 \%)$ & $7(7.54 \%)$ & & $16(17.20 \%)$ & $6(6.46 \%)$ & \\
Total & $59(63.41 \%)$ & $34(36.59 \%)$ & & $60(64.47 \%)$ & $33(35.53 \%)$ & \\
\hline Weekly visit days & $5.74 \pm 0.38$ & $7.00 \pm 0.00$ & 0.137 & $6.09 \pm 0.36$ & $5.5 \pm 0.72$ & 0.326 \\
Daily hours with patient & $2.74 \pm 0.45$ & $1.50 \pm 0.50$ & 0.771 & $2.7 \pm 0.49$ & $3.0 \pm 1.32$ & 0.635 \\
\hline
\end{tabular}


were kept and the safety of the material was safeguarded. The anonymity of the test was patented and the results were used solely for the purposes of the research and only by this research group. The stress or emotion of the test on the participants was limited to a minimum. The reliability of the results obtained ensured the accurate and complete description of the methods, the sample material and the general conditions of the survey.

\section{Results}

In Table 1 characteristics of family members are presented. From the data it can be concluded that the mean age of respondents was 49.4 years. Females composed $84.6 \%(\mathrm{~N}=78)$ of the sample. It can be seen that most of them were spouses of patients (42.3\%) followed by sib- lings (19.2\%) and offsprings (11.5\%). Their level of education ranged between less than high school graduates (15.4\%), and university graduates (23.4\%). Most of participants were married (92.5\%) and household keepers (45.16\%) who live with the patient (61.5\%) and their house is at the place where the hospital is (63.4\%). They also reported a mean of 5 visitation days per week, and a mean of approximately 1.30 hours per day spent with the patient.

Comparing the demographic characteristics of family members and level of satisfaction and family expectations those that were associated were level of education and relationship to the patient. Variables that were found to correlate with family members' satisfaction were their relationship with patient $(\mathrm{P}=0.004)$ and level of education $(\mathrm{P}=0.013)$. In addition, their expectations from nurses were correlated with level of education $(\mathrm{P}=0.023)$ (Table 2).

Table 3. Comparisons between family members' perceptions of behavioral role expectations and perceived role enactment of nurses.

\begin{tabular}{|c|c|c|}
\hline Family response items & Mean \pm SE & $\mathbf{P}$ \\
\hline $\begin{array}{l}\text { Ask me to leave during procedures } \\
\text { Perceived role enactment } \\
\text { Behavioral role expectation }\end{array}$ & $\begin{array}{c}2.49 \pm 0.14 \\
2.521 \pm 0.17\end{array}$ & 0.523 \\
\hline $\begin{array}{l}\text { Talk about the patient's prognosis } \\
\text { Perceived role enactment } \\
\text { Behavioral role expectation }\end{array}$ & $\begin{array}{l}2.84 \pm 0.17 \\
3.43 \pm 0.19\end{array}$ & 0.001 \\
\hline $\begin{array}{l}\text { Explain equipment } \\
\text { Perceived role enactment } \\
\text { Behavioral role expectation }\end{array}$ & $\begin{array}{l}3.24 \pm 0.17 \\
3.60 \pm 0.16\end{array}$ & 0.000 \\
\hline $\begin{array}{l}\text { Explain what I expect to see for first time } \\
\text { Perceived role enactment } \\
\text { Behavioral role expectation }\end{array}$ & $\begin{array}{l}2.84 \pm 0.22 \\
3.12 \pm 0.14\end{array}$ & 0.004 \\
\hline $\begin{array}{l}\text { Ask how am I coping with the situation } \\
\text { Perceived role enactment } \\
\text { Behavioral role expectation }\end{array}$ & $\begin{array}{l}2.45 \pm 0.26 \\
2.66 \pm 0.21\end{array}$ & 0.002 \\
\hline $\begin{array}{l}\text { Ask how illness affected my children } \\
\text { Perceived role enactment } \\
\text { Behavioral role expectation }\end{array}$ & $\begin{array}{l}1.96 \pm 0.16 \\
2.34 \pm 0.12\end{array}$ & 0.011 \\
\hline $\begin{array}{l}\text { Make sure I know their names } \\
\text { Perceived role enactment } \\
\text { Behavioral role expectation }\end{array}$ & $\begin{array}{l}3.55 \pm 0.15 \\
3.79 \pm 0.12\end{array}$ & 0.344 \\
\hline $\begin{array}{l}\text { Make me feel that I can ask questions } \\
\text { Perceived role enactment } \\
\text { Behavioral role expectation }\end{array}$ & $\begin{array}{l}3.66 \pm 0.11 \\
3.79 \pm 0.13\end{array}$ & 0.567 \\
\hline $\begin{array}{l}\text { Let me spend as much time with the patient } \\
\text { Perceived role enactment } \\
\text { Behavioral role expectation }\end{array}$ & $\begin{array}{l}2.40 \pm 0.21 \\
2.59 \pm 0.16\end{array}$ & 0.000 \\
\hline $\begin{array}{l}\text { Let me help take care of the patient } \\
\text { Perceived role enactment } \\
\text { Behavioral role expectation }\end{array}$ & $\begin{array}{l}2.68 \pm 0.23 \\
2.89 \pm 0.23\end{array}$ & 0.610 \\
\hline $\begin{array}{l}\text { Make me feel I can phone at any time } \\
\text { Perceived role enactment } \\
\text { Behavioral role expectation }\end{array}$ & $\begin{array}{l}3.10 \pm 0.08 \\
2.89 \pm 0.07\end{array}$ & 0.753 \\
\hline $\begin{array}{l}\text { Help me be near and communicate with patient } \\
\text { Perceived role enactment } \\
\text { Behavioral role expectation }\end{array}$ & $\begin{array}{l}3.65 \pm 0.12 \\
3.31 \pm 0.15\end{array}$ & 0.197 \\
\hline $\begin{array}{l}\text { Total score } \\
\text { Perceived role enactment } \\
\text { Behavioral role expectation } \\
\end{array}$ & $\begin{array}{l}2.99 \pm 0.11 \\
3.42 \pm 0.08\end{array}$ & 0.002 \\
\hline
\end{tabular}

In Table 3 comparisons between family members' perceptions of behavioral role expectations and perceived role enactment of nurses are presented. Nurses' performance was lower than their expectations in the areas of discussing patient diagnosis $(\mathrm{P}=0.001)$, explaining equipment $(\mathrm{P}=0.000)$, preparing them for their first visit $(\mathrm{P}=0.004)$, asking about how they are coping with the situation $(\mathrm{P}=0.002)$, advising about how critical illness could affect children $(\mathrm{P}=0.011)$ and letting them spend time with patient $(\mathrm{P}=0.000)$. Total behavioral role expectation score was statistically different from the total perceived role enactment score $(\mathrm{P}=0.002)$.

\section{Discussion}

In Greece no other study till now was made to examine family perceptions of nurses' roles with family members and the factors that influence their perceptions of that role. The findings of this study suggest that family members expect that nurses should make an effort to fulfill their needs. This study also demonstrated that nurses failed to meet family members' expectations with respect to some specific interventions that follow: explaining patients' prognoses, explaining equipment used with patients, preparing family members for their first visits, inquiring how they are coping with the situation, advising about how critical illness could affect children and letting them spend time with patient. This study finding showed that family members perceived that nurses intervened to address their emotional needs. Long and Greeneich ${ }^{19}$ and Aspinal and his colleagues, ${ }^{20}$ explained that satisfaction is a result of fulfilling one's needs and those who report great degree of satisfaction with nursing care are those whose expectations are met. If there is a difference between expectations and behaviors, that could lead to conflict and dissatisfaction. So nurses can better assist family members to cope and meet their expectations by addressing their needs having in mind their relationship to patients and their educational level. It can be concluded that those who are highly educated demand more because they tend to be better informed and therefore demand higher quality services. In a similar study conducted by Lee et al. ${ }^{13}$ concerning the needs of families with a relative in a critical care unit in Hong Kong, it has been found that families often look for hope and honest information about patient's conditions.

Additionally, Hinkle and Fitzpatrick conducted a similar study in 2011 in order to investigate the differences between the perceptions of American relatives, physicians and nurses concerning the needs of relatives visiting intensive care patients. ${ }^{21}$ In this study rela- 
tives of patients in critical care units were able to identify their needs and indicated that many resources were available and used to meet their needs.

\section{Conclusions}

In conclusion, the results of this study indicate that nurses met family members' expectations and that led to satisfied participants. Further research could be conducted on family perceptions of nurses' roles toward family members.

\section{Limitation of study}

One limitation of this study was the use of self-report instruments, which may carry a degree of response bias something that was minimized by ensuring anonymity of participants and allowing their privacy during completion of the questionnaires.

\section{References}

1. Fox-Wasylyshyn SM, El-Marsi MM, Williamson KM. Family perceptions of nurses' roles toward family members of critically ill patients: A descriptive study. Heart Lung 2005;34:335-44.

2. Stayt LC. Nurses' experiences of caring for families with relatives in intensive care units. J Adv Nurs 2007;57:623-30.

3. Maxwell KE, Stuenkel D, Saylor C. Needs of family members of critically ill patients: a comparison of nurse and family perceptions. Heart Lung 2007;36:367-76.

4. Hweidi IM. Jordanian patients' perception of stressors in critical care units: a questionnaire survey. Int J Nurs Stud 2007;44: 227-35.

5. Zaforteza C, Gastaldo D, De Pedro JE, et al. The process of giving information to families of critically ill patients: a field of tension. Int J Nurs Stud 2005;42:135-45.

6. Takman C, Severinsson E. The needs of significant others within intensive care: the perspectives of Swedish nurses and physicians. Intensive Crit Care Nurs 2004;20:22-31.

7. Takman C, Severinsson E. Comparing Norwegian nurses' and physicians' perceptions of the needs of significant others in Intensive Care Units. J Clin Nurs 2005;14:621-31.

8. Takman C, Severinsson E. A description of healthcare providers' perceptions of the needs of significant others in intensive care units in Norway and Sweden. Intensive Crit Care Nurs 2006;22:228-38.

9. Obringer K, Hilgenberg C, Booker K. Needs of adult family members of intensive care unit patients. J Clin Nurs 2012;21:1651-8.

10. Leung KK, Chien WT, Mackenzie AE. Needs of Chinese Families of Critically Ill
Patients. West J Nurs Res 2000;2:826-40.

11. Downey L, Engelberg RA, Shannon SE, Curtis JR. Measuring intensive care nurses' perspectives on family-centered endof-life care: evaluation of 3 questionnaires. Am J Crit Care 2006;15:568-79.

12. Patistea E, Babatsikou F. Parents' perceptions of the information provided to them about their child's leukaemia. Eur J Oncol Nurs 2003;7:172-81.

13. Lee IYM, Chien WT, Mackenzie AE. Needs of families with a relative in a critical care unit in Hong Kong. J Clin Nurs 2000;9:4654.

14. Waters CM. Professional nursing support for culturally diverse family members of critically ill adults. Res Nurs Health 1999; 22:107-17.

15. Høye S, Severinsson E. Professional and cultural conflicts for intensive care nurses. J Adv Nurs 2010;66:858-67.

16. Auerbach SM, Kiesler DJ, Wartella J, et al. Optimism, satisfaction with needs met, interpersonal perceptions of the healthcare team, and emotional distress in patients' family members during critical care hospitalization. Am J Crit Care 2005; 14:202-10.

17. Garrouste-Orgeas M, Willems V, Timsit JF, et al. Opinions of families, staff, and patients about family participation in care in intensive care units. J Crit Care 2010; 25:634-40. 